\section{Drug Shortages: What Does France Do Better than Canada?}

Reports of drug shortages date back to the $1970 \mathrm{~s},{ }^{1,2}$ but recent years have seen an increase in the number and severity of supply shortages. Recently, Vogel $^{3}$ commented on the limitations of the Canadian drug shortage registry that has been developed over the past 2 years, and Duffin ${ }^{4}$ commented on the current drug shortage crisis involving Sandoz products.

Our pharmacy research team investigated the magnitude of the problem and documented a total of 493 drug shortages in Canada in 2006, 400 in 2007, 442 in 2008, 680 in 2009, and 385 in the first 8 months of 2010 . $^{5}$ We also documented a total of 429 drug shortages over the 12-month period from September 2010 to August 2011. ${ }^{6}$ In response to this sustained shortage of drugs, we developed a website to support clinicians in their management of drug shortages (www.fridaypm.ca). In the past few years, Apotex (in 2009), ${ }^{7}$ Teva (in 2011), ${ }^{8}$ and other Canadian drug manufacturers have received warning letters from the US Food and Drug Administration (FDA) concerning deviations from US good manufacturing practices. More recently, in 2011, Novartis International AG (the parent company of Sandoz Canada) received a similar notice from the FDA. ${ }^{9}$ In response, following an extensive internal analysis of the issues raised by the FDA, Sandoz sent a letter to customers on February 15, 2012, stating that the company had expanded the remediation actions already under way and that it had opted to discontinue certain injectable products and to temporarily suspend the production of others. ${ }^{10}$ The impact of these actions was an acute shortage of numerous parenteral drug products in Canada.

In this context of sustained drug shortages involving various manufacturers, we explored and compared the current situation in Canada and France. On 4 consecutive Fridays in March 2012, we extracted data on the current number of drug shortages and the drug manufacturers involved from 2 key public websites, our own in Canada (www.fridaypm.ca) and one in France (www.ansm.sante.fr). We found a substantial difference between the 2 countries, with 7-8 times the number of shortages in Canada as in France (Table 1). The Canadian situation was very worrisome, with almost 200 common drug items in short supply, in contrast to fewer than 40 in France.

The high level of drug shortages has had a major impact on hospital pharmacists' workload and poses a serious risk to patient care. During the current crisis, hospital pharmacists, physicians, and other clinicians have expended considerable time and effort to identify alternative treatment options, according to patients' needs and the resources available to each particular hospital.

What could explain the magnitude of the difference in drug shortages between these 2 industrialized countries? Many causes of drug shortages have been identified, including shortages of raw materials, manufacturing issues, the legal environment, industry reorganization, the grey market for drugs, third-party reimbursement rules, and contractual practices. ${ }^{11}$ More specifically, in 2002, France put in place a preventive notification procedure for potential drug shortages. In 2004, the country adopted legislative changes requiring drug manufacturers to provide notification of any potential and actual drug shortages. ${ }^{12}$ Similar legislative changes are now being discussed in the United States. ${ }^{13}$ Although we cannot say with certainty which factors explain the discrepancy between France and Canada, the preventive actions taken in France have likely contributed to keeping drug shortages in that country at a relatively low level.

SigmaSanté, a drug purchasing group in Quebec, has taken action by introducing contract clauses that require mandatory reporting of drug shortages by drug manufacturers. These clauses, which took effect on April 1, 2012, include the mandatory reporting of drug shortages on the CHU Sainte-Justine website

Table 1. Comparison of Drug Shortages in Canada and France, March 2012

\begin{tabular}{lcc} 
& \multicolumn{2}{c}{ Mean \pm SD* } \\
\cline { 2 - 3 } Variable & Francet & Canadał \\
\hline No. of drug products in shortage & $46.8 \pm 3.0$ & $347.3 \pm 22.4$ \\
No. of manufacturers with at least one product & $21.0 \pm 1.6$ & $14.0 \pm 1.4$ \\
in shortage & & $19.4 \pm 11.4$ \\
No. of drug products in shortage per manufacturer & $2.2 \pm 0.1$ & $177.5 \pm 15.8$ \\
No. of generic drugs in short supply & $34.3 \pm 2.1$ & $2.0 \pm 0.1$ \\
No. of shortages per generic drug & $1.4 \pm 0.0$ & \\
\hline ANSMS = Agence nationale de sécurité du médicament et des produits de santé \\
(formerly Agence française de sécurité sanitaire des produits de santé [AFSSAPS]), \\
SD = standard deviation. \\
*Based on data extracted on 4 consecutive Fridays in March 2012. \\
†Data obtained from ANSMS website (www.ansm.sante.fr). \\
fData obtained from CHU Sainte-Justine website (www.fridaypm.ca).
\end{tabular}


(www.fridaypm.ca). Additionally, we believe that legislative changes should be adopted in Canada, not only to mandate the reporting of actual and potential drug shortages by Canadian drug manufacturers, but also to ensure that the manufacturing and distribution of critical drugs do not rely on a single-source manufacturer. The current shortage of Sandoz products has convinced physicians, pharmacists, and other stakeholders of the significance of the problem, in terms of both clinician workload and, more importantly, patient safety. Pharmacists and physicians should be kept aware of trends in drug shortages to enable them to appropriately manage drug use in the face of ongoing shortages. Comparisons of the current drug shortage situation in Canada with shortages in other countries should be carried out to identify optimal legislative and contractual changes that could be adopted in Canada.

\section{References}

1. Stolar MH. Drug shortages. Science 1976;192(4235):94.

2. Kubica AJ, Bowman G. Letter: A statewide drug shortage reporting system. Am J Hosp Pharm 1976;33(7):628-631.

3. Vogel L. Online drug shortage registry "limited" in application. CMAJ 2012;184(3):E165-E166.

4. Duffin J. Canadian drug shortage: recent history of a mystery. CMAJ 2012;184(8):1000.

5. Bussières JF, Chiveri A, Lebel D. Perspectives sur les ruptures d'approvisionnement de médicaments en établissement de santé de 2006 à 2010. Can J Hosp Pharm 2011;64(6):426-435.

6. Ottino G, Lebel D, Bussières JF. Drug shortages in health care institutions: perspectives in early 2012 [letter]. Can J Hosp Pharm 2012;65(2):151-152.

7. Inspections, compliance, enforcement, and criminal investigations: Apotex Inc [warning letter]. Silver Spring (MD): Food and Drug Administration (US); 2009 Jun 25 [cited 2012 Apr 24]. Available from: www.fda.gov/ ICECI/EnforcementActions/WarningLetters/ucm 170912.htm

8. Inspections, compliance, enforcement, and criminal investigations: Teva Pharmaceutical Industries 1/31/11 [warning letter]. Silver Spring (MD): Food and Drug Administration (US); 2011 Jan 31 [cited 2012 Apr 24]. Available from: www.fda.gov/ICECI/EnforcementActions/WarningLetters/ucm253437.htm

9. Inspections, compliance, enforcement, and criminal investigations: Novartis International AG 11/18/11 [warning letter]. Silver Spring (MD): Food and Drug Administration (US); 2011 Nov 18 [cited 2012 Apr 24]. Available from: www.fda.gov/ICECI/EnforcementActions/WarningLetters/ucm281843.htm

10. Lettre aux clients [15-16 février 2012]. Boucherville (QC): Sandoz Canada; 2012 [cited 2012 Sep 13]. Available from: www.sandoz.ca/site/ $\mathrm{fr} /$ products/inventaire/customerletter/letter 1. shtml?licensecode=catalogue (registration required to access content)

11. ASHP Expert Panel on Drug Product Shortages; Fox ER, Birt A, James KB, Kokko H, Salverson S, Soflin DL. ASHP guidelines on managing drug product shortages in hospitals and health systems. Am J Health Syst Pharm 2009;66(15):1399-1406.

12. Ottino G, Lebel D, Bussières JF, Bourdon O. Gestion des ruptures d'approvisionnement de médicaments : perspectives en France, aux ÉtatsUnis et au Canada. Can J Hosp Pharm 2012;65(1):37-42.

13. Yukhananov A. Drug shortage bill may ride U.S. highway legislation. Reuters; 2012 Feb 14 [cited 2012 Apr 24]. Available from: www.reuters.com/ article/2012/02/14/us-drug-shortage-bill-idUSTRE81D21T20120214

\section{Isabelle Barthélémy}

Pharmacy Intern and Research Assistant

Pharmacy Practice Research Unit

Jean-François Bussières, BPharm, MSC, FCSHP

Head

Pharmacy Department and Pharmacy Practice Research Unit

Denis Lebel, BPharm, MSC, FCSHP

Assistant Head

Pharmacy Department and Pharmacy Practice Research Unit
Pierre Gaudreault, MD

Pediatrician, Department of Pediatrics

CHU Sainte-Justine

Montréal, Quebec

Sonia Prot-Labarthe, PharmD, PhD, APHP

Pharmacist

Olivier Bourdon, PharmD, PhD, APHP

Pharmacist

Hôpital Robert Debré and Université Paris Descartes

Paris, France

Jean-François Bussières is also Professor in the Faculty of Pharmacy, Université de Montréal, Montréal, Quebec. Dr Gaudreault is also Professor in the Faculty of Medicine, Université de Montréal, Montréal, Quebec. 